\title{
Níveis de Energia em Dietas para Ovinos Santa Inês: Digestibilidade Aparente ${ }^{1}$ \\ Kaliandra Souza Alves ${ }^{2}$, Francisco Fernando Ramos de Carvalho ${ }^{3}$, Antônia Sherlânea Chaves Véras $^{3}$, Marcelo de Andrade Ferreira ${ }^{3}$, Roberto Germano Costa ${ }^{4}$, Elisângela Pereira dos Santos $^{5}$, Cleber Rondinelli Gomes de Freitas ${ }^{5}$, Célio Marques dos Santos Júnior ${ }^{6}$, Dulciene Karla Bezerra de Andrade ${ }^{7}$
}

RESUMO - Os coeficientes de digestibilidade aparente de matéria seca (CDAMS), matéria orgânica (CDAMO), proteína bruta(CDAPB), extrato etéreo (CDAEE), carboidratos totais (CDACHOT), carboidratos não-fibrosos (CDACNF), fibra em detergente neutro (CDAFDN) e fibra em detergente ácido (CDAFDA) foram determinados para avaliar o efeito de níveis crescentes de energia na dieta. A estimativa de digestibilidade aparente dos nutrientes, utilizando-se os métodos de coleta total de fezes, e a estimativa da produção de matéria seca fecal (PMSF), empregando-se a fibra em detergente ácido indigestível (FDAI) como indicador interno, também foram comparadas. Utilizaram-se 18 ovinos Santa Inês, machos não-castrados, com idade média de seis meses e peso vivo médio de $20 \mathrm{~kg}$, alimentados com dietas contendo 2,42; 2,66; e 2,83 Mcal de energia metabolizável/kg de matéria seca, distribuídos em delineamento em blocos casualizados, com seis repetições. A estimativa da PMSF, utilizando-se a FDAI, foi efetuada para posterior comparação com a PMSF, determinada pelo método de coleta total de fezes. Para os CDAMS, CDAMO, CDAEE, CDACHOT e CDACNF, houve efeito linear crescente com o aumento nos níveis de energia; no entanto, para os CDAFDN e CDAFDA, observou-se efeito linear decrescente e, para o CDAPB, não houve efeito com o aumento nos níveis de energia da dieta. Conclui-se que a FDAI pode ser utilizada como indicador interno para estimativa do coeficiente de digestibilidade em ovinos.

Palavras-chave: alimentos, concentrado, FDAI, indicador, nutrientes

\section{Dietary Energy Levels for Santa Inês Sheep: Apparent Digestibility}

\begin{abstract}
The coefficients of apparent digestibility of dry matter (CADDM), organic matter (CADOM), crude protein (CADCP), ether extract (CADEE), total carbohydrates (CADTCHO), nonfiber carbohydrates (CADNFC), neutral detergent fiber (CADNDF) and acid detergent fiber (CADADF) were determined to evaluate the effect of the increasing dietary energy levels. The estimate of the apparent digestibility of the nutrients, using the method of fecal total collection, and the estimate of fecal dry matter production (FDMP), by the indigestible acid detergent fiber (IADF), as internal marker, were also compared. Eighteen Santa Inês sheep (averaging live weight of $20 \mathrm{~kg}$ and six months old) were full fed diets with 2.42; 2.66 and $2.83 \mathrm{Mcal}$ metabolizable energy/kg of dry matter and allotted to a randomized block design, with six replicates. FDMP estimate, using IADF, was performed to be compared with the FDMP, determined by the total feces collection. It was observed increasing linear effect for CADDM, CADOM, CADEE, CADTCHO and CADNFC, as the the dietary energy levels increased. However, CADNDF and CADADF decreased linearly and, for CADCP, there was no effect, as the the dietary energy levels increased. IADF can be used as internal marker to estimate the coefficient of apparent digestibility in sheep.
\end{abstract}

Key Words: concentrate, feed, indicator, nutrients

\section{Introdução}

Na prática de criação de ruminantes, a alimentação é responsável pela maior parte dos custos, sendo de fundamental importância conhecer os princípios básicos sobre os alimentos, suas características e composição química, visando a formulação de dietas balanceadas para suprir as necessidades dos animais, explorando sua máxima capacidade digestiva, conseguindo atingir todo seu potencial genético para aproveitamento da dieta consumida (Dutra et al., 1997).

A avaliação do valor nutritivo dos alimentos consumidos pelos animais é um desafio constante para os nutricionistas. De acordo com Cardoso et al. (2000), o principal objetivo é ajustar a quantidade e qualidade da dieta baseando-se nas exigências dos animais.

Uma forma de se avaliar a qualidade do alimento é através da determinação de sua digestibilidade.

\footnotetext{
1 Parte da dissertação apresentada pelo primeiro autor à Universidade Federal Rural de Pernambuco.

2 Doutoranda em Zootecnia. Bolsista do CNPq. E.mail: kally alves@hotmail.com

3 Professor do DZ/UFRPE. E.mail: ffrcarva@ufrpe; ferreira@ufrpe; sherlanea@ig.com.br

${ }^{4}$ Professor do DAP/CCA/UFPB. E.mail: rgermano@cft.ufpb.br

5 Aluno de graduação Zootecnia - UFRPE.

${ }^{6}$ Bolsista-PIBIC/CNPq.

${ }^{7}$ Mestre em Zootecnia.E.mail: kakazoo@ig.com.br
} 
Segundo Van Soest (1994), digestão pode ser definida como um processo de conversão de macromoléculas dos nutrientes em compostos mais simples, que podem ser absorvidos a partir do trato gastrintestinal, e medidas de digestibilidade servem para qualificar os alimentos quanto ao seu valor nutritivo, expressa pelo coeficiente de digestibilidade, que indica a quantidade percentual de cada nutriente do alimento que o animal tem condição de utilizar.

Existem vários fatores que podem influenciar a digestibilidade, como a composição e preparo dos alimentos e da dieta, além de fatores dependentes dos animais e do nível nutricional, especialmente a densidade energética da ração.

De modo geral, o aumento na proporção de energia na dieta leva à melhoria em sua digestibilidade. Contudo, quando grande quantidade de energia é adicionada à dieta de ruminantes, devido à adição de concentrado, ocorre aumento na taxa de passagem da digesta pelo rúmen, acarretando menor tempo de colonização da população microbiana e, por conseguinte, diminuição da digestibilidade da fibra em decorrência do aumento nas proporções dos carboidratos prontamente disponíveis e fermentáveis (Ørskov, 2000; Valadares Filho et al., 2000; Mertens, 2001). Além disso, a excessiva redução nos níveis de fibra nas dietas de ruminantes poderá ser prejudicial à digestibilidade total dos alimentos, visto que a fibra é fundamental para a manutenção das condições ótimas do rúmen, pois altera as proporções de ácidos graxos voláteis, estimula a mastigação e mantém o pH em níveis adequados para à atividade microbiana, que está na faixa de 6,8 e 6,5 (Mertens, 1992; Allen, 1997; Grant \& Mertens, 1992).

Avaliando três níveis de energia, 2,4; 2,5; e 2,7 Mcal de energia metabolizável (EM)/kg de matéria seca (MS), em cordeiros Omani em crescimento, Mahgoub et al. (2000) encontraram coeficientes de digestibilidade da MS de 66,$9 ; 68,7 ;$ e 73,9\%, respectivamente. Já Ferreira et al. (2000), trabalhando com ovinos sem raça definida (SRD), alimentados com dietas contendo 2,54; 2,48; 2,57; e 2,61 Mcal de EM/kg de MS, encontraram coeficientes de digestibilidade da matéria seca(CDMS) de: 62,85; 61,57; 62,74; e 62,40\% e 72,93; 71,55; 75,56; e 74,60\% para coeficientes de digestibilidade matéria orgânica (CDAMO).

Hussein et al. (1995) e Dutra et al. (1997) observaram maiores CDAMS e CDAMO, para rações com maiores teores de energia. Por outro lado, Carvalho et al. (1997) e Véras et al. (2000) verificaram comporta- mento quadrático para o CDMS CDMO, quando elevaram os níveis de energia da dieta de bovinos.

A digestibilidade dos nutrientes dos alimentos em ovinos pode ser determinada pelo método de coleta total de fezes, mas também pode ser estimada por meio de indicadores internos, presentes no alimento.

A recuperação de frações indigestíveis do alimento é a base para uso de indicadores internos, que são empregados convenientemente em estudos nos quais sãonecessárias estimativas de digestibilidade (Van Soest, 1994). Devido à simplicidade e conveniência de utilização de indicadores, uma série de informações pode ser proporcionada, incluindo a quantidade ingerida de alimentos ou nutrientes específicos, a taxa de passagem da digesta por todo trato digestivo e a digestibilidade de todo alimento ou nutriente específico (Zeoula et al., 2001). Neste contexto, a fibra indigestível em detergente ácido (FDAI), após 144 horas de incubação in vitro ou in situ, tem sido utilizada em estudos de digestiblilidade (Conchran et al., 1986; Berchielli et al., 2000); Itavo et al. (2001).

O presente trabalho foi conduzido com o objetivo de avaliar o efeito de níveis crescentes de energia sobre os coeficientes de digestibilidade aparente de matéria seca (CDAMS), proteína bruta (CDAPB), matéria orgânica (CDAMO), extrato etéreo (CDAEE), carboidratos totais (CDACHOT), carboidratos não -fibrosos (CDACNF), fibras em detergente neutro (CDAFDN) e fibra em detergente ácido (CDAFDA), comparar a estimativa de digestibilidade aparente, dos nutrientes utilizando-se os métodos de coleta total de fezes e estimativa da produção de matéria seca fecal (PMSF) empregando FDAI como indicador interno, em ovinos Santa Inês.

\section{Material e Métodos}

Este trabalho foi conduzido, no Galpão de Desempenho e Digestibilidade do Setor de Caprinoovinocultura do Departamento de Zootecnia da Universidade Federal Rural de Pernambuco - UFRPE, localizada em Recife-PE, situada na micro-região fisiográfica do Litoral Mata, pertencente à Região Metropolitana do Recife - RMR.

Foram utilizados 18 ovinos Santa Inês, machos não-castrados, em crescimento, com idade média de seis meses e peso vivo médio inicial de $20 \mathrm{~kg}$. Os animais foram alojados, individualmente, em gaiolas, medindo $1,1 \mathrm{~m} \times 0,55 \mathrm{~m}$, providas de comedouros e bebedouros e com dispositivo para coleta de fezes e

R. Bras. Zootec., v.32, n.6, p.1962-1968, 2003 (Supl. 2) 
urina, onde receberam os tratamentos experimentais, constituídos por feno de capim Tífton-85 (Cynodon dactylon), moído em máquina forrageira com peneira de crivo de $8 \mathrm{~mm}$ e diferentes níveis de concentrado, à base de milho e farelo de soja, resultando em diferentes níveis de energia $(2,42 ; 2,66$; e $2,83 \mathrm{Mcal}$ de energia metabolizável $[\mathrm{EM}] / \mathrm{kg}$ de matéria seca [MS]). Uma mistura mineral foi acrescentada ao concentrado (Tabelas 1, 2 e 3). A ração de maior nível de EM foi formulada para atender aos requerimentos de ganhos de peso diários médios de $300 \mathrm{~g} /$ animal/dia, segundo o NRC (1985).

Inicialmente, os animais foram pesados, identificados e tratados contra ecto e endoparasitas. Em seguida, passaram por um período de adaptação de 28 dias às instalações, em que receberam o mesmo tratamento (50\% volumoso e $50 \%$ concentrado), quando foi estimada a quantidade de alimento ingerida para estabelecer $10 \%$ de sobras, fazendo-se reajuste diário da quantidade oferecida, procedimento que também foi adotado para fase de coleta de dados. Decorrido este tempo, os animais foram sorteados aleatoriamente nos respectivos tratamentos experimentais, onde permaneceram por 28 dias, após os quais foi realizada a coleta de amostras, durante cinco dias.

Os alimentos foram fornecidos duas vezes ao dia, na forma de ração completa, com água permanentemente à disposição dos animais.

As quantidades de ração oferecida e sobras foram registradas diariamente, durante os cinco dias de coleta. Nesse período, também foram coletadas e pesadas, as fezes excretadas para determinação da produção de matéria seca fecal (PMSF), que foram, igualmente, amostradas, identificadas e armazenadas a $-15^{\circ} \mathrm{C}$. Posteriormente, todas as amostras foram pré-secas em estufa ventilada a $65^{\circ} \mathrm{C}$ e misturadas, para constituir uma amostra composta, que foi homogeneizada, retirando-se uma alíquota representativa, que foi moída em moinho com peneira de crivo de $1 \mathrm{~mm}$, para posteriores análises laboratoriais.

A estimativa da PMSF, utilizando-se a fibra em detergente ácido indigestível (FDAI) como indicador, foi efetuada para posterior comparação com a produção de MS fecal determinada pelo método de coleta total de fezes.

Amostras de fezes, alimentos e sobras foram incubadas no rúmen de um bovino macho, adulto, mestiço, castrado, por um período de 144 horas, em sacos tipo ANKON, segundo metodologia descrita por Berchielle et al. (2000), exceto quanto à incubação, que foi in situ. A quantidade da amostra incubada foi de $1,0 \mathrm{~g}$ para alimentos concentrados e $0,5 \mathrm{~g}$ para feno, fezes e sobras. O material remanescente da incubação foi submetido à extração com detergente ácido, cujo resíduo foi considerado FDAI.

As determinações, tanto para o método de coleta total de fezes, quanto para o método de estimativa da PMSF com FDAI, de matérias seca (MS), orgânica (MO) e mineral (MM), nitrogênio total, extrato etéreo (EE) e fibra em detergente ácido (FDA) foram realizadas conforme técnicas descritas por Silva (1990), sendo que a proteína bruta $(\mathrm{PB})$ foi obtida pelo produto entre o teor de nitrogênio total e o fator 6,25; e a determinação da fibra em detergente neutro (FDN), de acordo com metodologia descrita por Van Soest et al. (1991).

Os carboidratos totais (CHOT), e consumo de

Tabela 1 - Teores de matéria seca (MS), proteína bruta (PB), extrato etéreo (EE), fibra em detergente neutro (FDN), fibra em detergente ácido (FDA), matéria orgânica (MO), matéria mineral (MM) e energia metabolizável (EM) dos ingredientes das dietas

Table 1 - Contents of crude protein (CP), ether extract (EE), neutral detergent fiber (NDF), acid detergent fiber (ADF), organic matter (OM), mineral matter (MM) and metabolizable energy (ME) of the ingredients of the diets

\begin{tabular}{|c|c|c|c|c|c|c|c|c|}
\hline \multirow[t]{3}{*}{$\begin{array}{l}\text { Ingredientes } \\
\text { Ingredients }\end{array}$} & \multirow[t]{3}{*}{$\begin{array}{c}\mathrm{MS}(\%) \\
D M\end{array}$} & \multicolumn{7}{|c|}{$\begin{array}{c}\text { Nutrientes (\% MS) } \\
\text { Nutrients (\% DM) }\end{array}$} \\
\hline & & PB & $\mathrm{EE}$ & FDN & FDA & MO & MM & $\mathrm{EM}$ \\
\hline & & $C P$ & $E E$ & $N D F$ & $A D F$ & $O M$ & $M M$ & $M E$ \\
\hline Milho & 87,62 & 9,73 & 4,66 & 15,76 & 3,18 & 98,54 & 1,45 & $3,15^{*}$ \\
\hline Corn & & & & & & & & \\
\hline Farelo de soja & 83,65 & 53,74 & 1,08 & 15,74 & 12,45 & 92,89 & 7,11 & $3,18^{*}$ \\
\hline $\begin{array}{l}\text { Feno de Tifton } \\
\text { Tifton hay }\end{array}$ & 89,00 & 7,38 & 1,45 & 84,91 & 42,22 & 93,30 & 6,69 & $1.88^{* *}$ \\
\hline
\end{tabular}

\footnotetext{
* Valores de tabela (NRC, 1985) (Values of table (NRC, 1985).

** Valor estimado a partir do teor de NDT obtido em ensaio de digestibilidade utilizando-se feno de Tifton como único alimento.

** Value estimated from TDN content obtained in digestibility trial using only Tifton hay as food.
} 
Tabela 2 - Composição percentual dos ingredientes das dietas

Table 2 - Percentage of the ingredients of the diets

\begin{tabular}{|c|c|c|c|}
\hline \multirow[t]{2}{*}{$\begin{array}{l}\text { Ingredientes } \\
(\% \mathrm{MS}) \\
\text { Ingredients } \\
(\% \text { DM) }\end{array}$} & \multicolumn{3}{|c|}{$\begin{array}{c}\text { Níveis de energia metabolizável } \\
\text { na dieta (Mcal/kg MS)* } \\
\text { Leves of metabolizable } \\
\text { energy of the diet (Mcal/kg DM) } \\
\end{array}$} \\
\hline & 2,42 & 2,66 & 2,83 \\
\hline $\begin{array}{l}\text { Milho } \\
\text { Corn }\end{array}$ & 14,15 & 35,08 & 56,41 \\
\hline $\begin{array}{l}\text { Farelo de soja } \\
\text { Soybean meal }\end{array}$ & 23,36 & 22,40 & 21,32 \\
\hline $\begin{array}{l}\text { Feno de tifton } \\
\text { Tifton hay }\end{array}$ & 61,70 & 41,43 & 20,86 \\
\hline $\begin{array}{l}\text { Calcário } \\
\text { Limestone }\end{array}$ & 0,30 & 0,60 & 0,91 \\
\hline $\begin{array}{l}\text { Sal mineral } \\
\text { Mineralized salt }\end{array}$ & 0,49 & 0,49 & 0,50 \\
\hline
\end{tabular}

* Obtidos, como valor médio de NDT das dietas, de seis animais em cada tratamento.

* Obtained as average value of dietary TDN of six animals in each treatment.

Tabela 3 - Teores de matéria seca (MS), proteína bruta $(\mathrm{PB})$, extrato etéreo (EE), carboidratos totais (CHOT), carboidratos não fibrosos (CNF), fibra em detergente neutro (FDN), fibra em detergente ácido (FDA), matéria mineral (MM), matéria orgânica (MO) e nutrientes digestíveis totais (NDT) das dietas

Table 3 - Contents of dry matter (DM), crude protein (CP), ether extract (EE), total carbohydrates (TCHO), nonfiber carbohydrates (NFC), neutral detergent fiber (NDF) acid detergent fiber (ADF), mineral matter (MM) organic matter (MO) and total digestible nutrients (TDN) of the diets

\begin{tabular}{|c|c|c|c|}
\hline \multirow[t]{2}{*}{$\begin{array}{l}\text { Nutrientes } \\
\text { Nutrients }\end{array}$} & \multicolumn{3}{|c|}{$\begin{array}{c}\text { Níveis de energia metabolizáve } \\
\text { na dieta (Mcal/kg MS })^{*} \\
\text { Leves of metabolizable } \\
\text { energy of the diet (Mcal/kg DM) }\end{array}$} \\
\hline & 2,42 & 2,66 & 2,83 \\
\hline $\operatorname{MS}(\%)(D M)$ & 87,57 & 87,36 & 87,16 \\
\hline $\mathrm{PB}^{* *}(C P)$ & 18,48 & 18,51 & 18,48 \\
\hline $\mathrm{EE}^{* *}(E E)$ & 1,82 & 2,49 & 3,17 \\
\hline $\mathrm{CHOT}^{* *}($ TCHO $)$ & 73,02 & 73,15 & 73,33 \\
\hline $\mathrm{CNF}^{* *}(N F C)$ & 14,72 & 28,92 & 43,37 \\
\hline $\mathrm{FDN}^{* *}(N D F)$ & 58,30 & 44,23 & 29,96 \\
\hline $\mathrm{FDA}^{* *}(A D F)$ & 29,40 & 21,39 & 13,26 \\
\hline $\operatorname{MM}^{* *}(M M)$ & 6,68 & 5,85 & 5,01 \\
\hline $\mathrm{MO}^{* *}(O M)$ & 93,32 & 94,14 & 94,98 \\
\hline $\operatorname{NDT}(\%)(T D N)$ & 66,90 & 73,72 & 78,33 \\
\hline
\end{tabular}

* Obtido como valor médio de NDT das dietas, de seis animais em cada tratamento.

* Obtained as average value of dietary TDN of six animals in each treatment.

** \% na MS.

**\% in DM.

R. Bras. Zootec., v.32, n.6, p.1962-1968, 2003 (Supl. 2) nutrientes digestíveis totais (NDT) foram obtidos conforme recomendações de Sniffen et al. (1992); e os carboidratos não fibrosos (CNF), segundo Mertens (1997) . Os teores de NDT, em percentagens, foram obtidos através da relação entre os consumos de NDT e MS. A energia digestível (ED) foi calculada como o produto entre o teor de NDT e o fator 4,409 e a concentração de EM foi considerada $82 \%$ da ED (Coelho da Silva \& Leão, 1979).

O delineamento experimental utilizado foi em blocos casualizados, com três tratamentos e seis repetições, fazendo-se a interpretação estatística dos resultados por meio de análises de variância e regressão, em função dos níveis de energia na dieta. Os pesos dos animais foram controlados nos blocos.

Os critérios utilizados para escolha das equações foram o comportamento biológico, coeficiente de determinação $\left(\mathrm{r}^{2}\right)$, que foi calculado como a relação entre a soma de quadrado de regressão e a soma de quadrado total, e a significância, para os parâmetros da regressão, obtida pelo teste t, para os níveis de 1 e $5 \%$ de probabilidade.

Para comparação entre os métodos de coleta total de fezes e indicador FDAI, foi realizada análise de variância em parcelas subdivididas, em que os tratamentos constituíram as parcelas e os métodos, as subparcelas, com posterior comparação de média pelo teste Tukey para o nível de 5\% de probabilidade.

\section{Resultados e Discussão}

Os consumos de matéria seca (MS), durante o período de coleta para os tratamentos com 2,42; 2,66 e 2,83 Mcal EM/kg MS, foram respectivamente, 0,$870 ; 0,850 \mathrm{e} 0,970 \mathrm{~kg} / \mathrm{dia}$, que não foram influenciados $(\mathrm{P}>0,05)$ pelo nível de energia da ração.

$\mathrm{Na}$ Tabela 4, estão apresentados os coeficientes médios de digestibilidade aparente dos nutrientes, expressos em porcentagem, os respectivos coeficientes de variação (CV), equações de regressão e coeficiente de determinação $\left(\mathrm{r}^{2}\right)$. Observa-se que todas as variáveis estudadas foram influenciadas linearmente pelo aumento nos níveis de energia na dieta, exceto a digestibilidade da proteína bruta.

$\mathrm{O}$ efeito linear $(\mathrm{P}<0,01)$ sobre a digestibilidade aparente da matéria seca (CDAMS) foi devido à maior concentração de energia, em conseqüência da elevação dos níveis de carboidratos não-fibrosos (CNF), em relação aos carboidratos estruturais nas rações com maiores proporções de concentrado, con- 
forme pode ser verificado na Tabela 3. Uma vez que os CNF apresentam digestibilidade aparente acima de $90 \%$ e os carboidratos estruturais, próxima de $50 \%$, a maior digestão da matéria seca (MS), quando se utilizaram maiores níveis de energia, pode ser verificada pois, geralmente, o incremento dos níveis energéticos de dietas proporciona melhoria da digestibilidade. Tendência semelhante foi encontrada por Mahgoub et al. (2000), quando avaliaram rações com 2,4; 2,5; e 2,7 Mcal EM/kg de MS, para cordeiros jovens, e verificaram coeficientes de digestibilidade da MS de 66,9; 68,7 ; e $73,9 \%$, respectivamente.

Outros autores corroboram com as repostas obtidas neste trabalho. Cardoso et al (2000), trabalhando com rações contendo níveis crescentes de concentrado em novilhos Limousin x Nelore, encontraram efeito linear crescente para os coeficientes de digestibilidade da MS. De modo semelhante, Hussein et al. (1995) e Dutra et al. (1997) obtiveram maiores CDAMS e matéria orgânica (CDAMO), em rações com maiores teores de energia. Entretanto, Véras et al. (2000) verificaram comportamento quadrático para a digestibilidade aparente da MS, em que o valor máximo foi de $69,33 \%$, quando trabalharam com bovinos Nelore. Vale salientar que esses autores alimentaram animais com níveis de concentrado entre 12,5 e $75 \%$.

A relação entre as porcentagens de nutrientes digestíveis totais (NDT) e fibra em detergente neutro (FDN) das dietas apresentou comportamento linear, representado pela equação: NDT $=222,67-2,4458$ $\operatorname{FDN}\left(r^{2}=0,99\right)$, que pode ser observado na Figura 1. De forma similar, a equação obtida para estimativa da digestibilidade aparente da matéria seca (DAMS), em função da FDN, foi: DAMS = 271,76 - 3,1282FDN $\left(r^{2}=0,98\right)$. Pode se observar, por meio destas equações, que as concentrações de FDN das dietas são inversamente correlacionadas com os níveis de energia expressos em NDT e com a DAMS. Em razão dos elevados coeficientes de determinação $\left(r^{2}\right)$ e alta correlação negativa $(r=0,99)$, pode-se inferir que o valor energético das rações pode ser estimado, com segurança, a partir das concentrações de FDN, procedimento extremamente simples e menos oneroso que análises laboratoriais e cálculos, já que o NDT é a forma mais utilizada para expressar a concentração energética das rações. Comportamentos semelhantes

Tabela 4 - Médias, coeficiente de variação (CV), equações de regressão (ER) e coeficiente de determinação ( $\left.\mathrm{r}^{2}\right)$, para os coeficientes de digestibilidade aparente de matéria seca (CDAMS), matéria orgânica (CDAMO), proteína bruta (CDAPB), extrato etéreo (CDAEE), carboidratos totais (CDACHOT) e não fibrosos (CDACNF), fibra em detergente neutro (CDAFDN) e fibra em detergente ácido (CDAFDA), em função dos níveis de energia metabolizável (EM) das dietas

Table 4 - Means, coefficients of variation (CV), regression equation (RE) and coefficient of determination $\left(r^{2}\right)$ for the coefficients of apparent digestibility of dry matter (CADDM), organic matter $(O M)$, crude protein $(C P)$, ether extract $(E E)$, total carbohydrates (TCHO), nonfiber carbohydrates (NFC), neutral detergent fiber (NDF) and acid detergent fiber (ADF), according to the dietary metabolizable energy levels (ME)

\begin{tabular}{|c|c|c|c|c|c|c|}
\hline \multirow[t]{2}{*}{$\begin{array}{l}\text { Variáveis } \\
\text { Variables }\end{array}$} & \multicolumn{3}{|c|}{$\begin{array}{c}\text { Níveis de EM (Mcal/kg MS) } \\
\text { ME levels }(\text { Mcal/kg DM) }\end{array}$} & \multirow[t]{2}{*}{$\mathrm{CV}(\%)$} & \multirow[t]{2}{*}{$\mathrm{ER}(R E)$} & \multirow[t]{2}{*}{$r^{2}$} \\
\hline & 2,42 & 2,66 & 2,83 & & & \\
\hline $\begin{array}{l}\text { CDAMS } \\
C A D D M\end{array}$ & 67,96 & 73,47 & 76,84 & 0,95 & $\mathrm{y}=13,19005+22,57568 \mathrm{EM}^{* *}$ & 0,98 \\
\hline $\begin{array}{l}\text { CDAMO } \\
\text { CADOM }\end{array}$ & 70,04 & 75,72 & 78,99 & 0,63 & $y=-5,01866+30,07389 \mathrm{EM}^{* *}$ & 0,98 \\
\hline $\begin{array}{l}\text { CDAPB } \\
C A D C P\end{array}$ & 79,07 & 79,28 & 74,51 & 4,15 & $y=77,62$ & \\
\hline $\begin{array}{l}\text { CDAEE } \\
C A D E E\end{array}$ & 61,16 & 67,86 & 76,63 & 8,10 & $y=-31,48413+37,91173 \mathrm{EM}^{* *}$ & 0,63 \\
\hline $\begin{array}{l}\text { CDACHOT } \\
\text { CADTCHO }\end{array}$ & 67,71 & 75,00 & 80,29 & 1,01 & $y=15,48878+22,52395 \mathrm{EM}^{* *}$ & 0,99 \\
\hline $\begin{array}{l}\text { CDACNF } \\
C A D N F C\end{array}$ & 81,03 & 92,34 & 96,16 & 3,50 & $y=-1,44446+34,59605 \mathrm{EM}^{* *}$ & 0,82 \\
\hline $\begin{array}{l}\text { CDAFDN } \\
C A D N D F\end{array}$ & 63,65 & 61,54 & 53,95 & 7,81 & $y=98,59167-14,73492 \mathrm{EM}^{*}$ & 0,27 \\
\hline $\begin{array}{l}\text { CDAFDA } \\
C A D A D F\end{array}$ & 55,51 & 52,91 & 38,04 & 16,96 & $\mathrm{y}=120,19999-27,05136 \mathrm{EM}^{*}$ & 0,28 \\
\hline
\end{tabular}

$C A D A D F$

*, ** Significativo a 5 e $1 \%$ de probabilidade, respectivamente pelo teste $\mathrm{T}$.

*,** Significant at 5 and $1 \%$ of probability, respectively, byT test. 


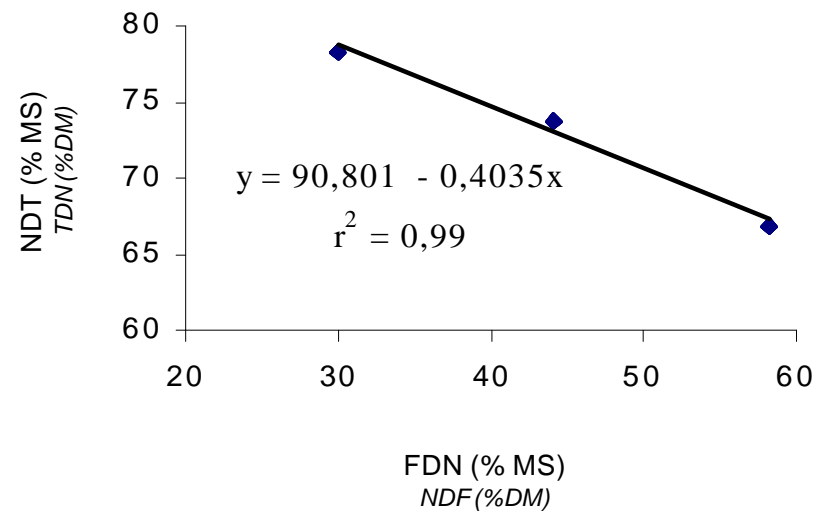

Figura 1 - Estimativa do teor de nutrientes digestíveis totais (NDT), em função da porcentagem de fibra em detergente neutro (FDN) das dietas.

Figure 1 - Estimate of the total digestible nutrients (TDN) content, in function of the dietary neutral detergent fiber (NDF) percentage.

foram encontrados por Tibo, et al. (2000) e Véras et al. (2000).

A redução na digestibilidade da FDN e FDA com o aumento dos níveis de energia na dieta pode ser atribuído à adição excessiva de amido às rações, que promove efeito depressivo sobre a digestibilidade ruminal da fibra e alterações nas condições ruminais. Coelho da Silva \& Leão (1979) também relataram que a adição de concentrado às dietas produz mudanças no processo de digestão e no metabolismo dos nutrientes, devido às interações entre os alimentos, denominadas efeito associativo.

A melhoria na digestibilidade da matéria orgânica (MO), extrato etéreo (EE), carboidratos totais (CHOT) e carboidratos não fibrosos (CNF), com o aumento dos níveis de energia das dietas, refletiu o mesmo comportamento verificado para a digestibilidade da MS. Por outro lado, a digestibilidade da proteína não foi influenciada, o que se deve, provavelmente, ao fato de as rações serem, isoprotéicas, como pode ser verificado na Tabela 3 .

Na Tabela 5, encontram-se os valores médios dos coeficientes de digestibilidade aparente estimados por meio de coleta total de fezes e da fibra em detergente ácido indigestível (FDAI), na qual se observa que não houve diferença significativa entre os métodos, para os componentes avaliados MS, PB, EE, FDN, FDA, CHOT, MO e CNF.

Estas observações permitem inferir que a FDAI pode ser utilizada como indicador interno para estimativa do coeficiente de digestibilidade em ovinos. Tais constatações podem contribuir para redução do trabalho envolvido quando da opção por estimar a produção fecal por meio de coleta total. Estes resultados corroboram os obtidos por Ítavo et al. (2001), que trabalharam com indicadores internos para estimativa da produção fecal e digestibilidade de nutrientes em bovinos, usando 20,40,60 e $80 \%$ de concentrado nas dietas e também encontraram boa estimativa da digestibilidade dos nutrientes com o uso do FDAI e, também, Berchielli et al. (2000), quando avaliaram indicadores internos em ensaios de digestibilidade, usando dietas compostas de $45 \%$ de concentrado e $55 \%$ de volumoso.

Foi verificado ainda que, à medida que se elevaram os níveis de energia na dieta $(2,42 ; 2,66$; e 2,83 Mcal EM/kg de MS), a quantidade de FDAI reduziu consideravelmente, cujos valores foram de 10,78;

Tabela 5 - Coeficientes de digestibilidade aparente das matéria seca (CDAMS) e matéria orgânica (CDAMO), proteína bruta (CDAPB), extrato etéreo (CDAEE), carboidratos totais (CDACHOT) e não-fibrosos (CDACNF), fibra em detergente neutro (CDAFDN) e fibra em detergente ácido (CDAFDA), utilizando-se coleta total de fezes (CTF) ou fibra detergente ácido indigestível (FDAI), e respectivos coeficientes de variação (CV)

Table 5 - Coefficients of apparent digestibility of dry matter (CADDM), organic matter (OM), crude protein $(C P)$, ether extract (EE), total carbohydrates (TCHO), nonfiber carbohydrates (NFC), neutral detergent fiber (NDF) and acid detergent fiber (ADF), using fecal total collection (FTC) or indigestible acid detergent fiber (IADF), and respective coefficients of variation (CV)

\begin{tabular}{|c|c|c|c|}
\hline \multirow[t]{2}{*}{$\begin{array}{l}\text { Variáveis (\%) } \\
\text { Variables (\%) }\end{array}$} & \multicolumn{2}{|c|}{$\begin{array}{l}\text { Métodos } \\
\text { Methods }\end{array}$} & \multirow[t]{2}{*}{$\mathrm{CV}(\%)$} \\
\hline & $\begin{array}{l}\text { CTF } \\
\text { FTC }\end{array}$ & $\begin{array}{l}\text { FDAI } \\
I A D F\end{array}$ & \\
\hline CDAMS & $72,76^{\mathrm{a}}$ & $73,87^{\mathrm{a}}$ & 4,06 \\
\hline $\begin{array}{l}C A D D M \\
\text { CDAMO } \\
C A D O M\end{array}$ & $74,92^{\mathrm{a}}$ & $75,90^{\mathrm{a}}$ & 3,84 \\
\hline $\begin{array}{l}\text { CDAPB } \\
C A D C P\end{array}$ & $77,62^{\mathrm{a}}$ & $78,92^{\mathrm{a}}$ & 3,43 \\
\hline $\begin{array}{l}\text { CDAEE } \\
C A D E E\end{array}$ & $68,55^{\mathrm{a}}$ & $69,55^{\mathrm{a}}$ & 8,23 \\
\hline $\begin{array}{l}\text { CDACHOT } \\
C A D T C H O\end{array}$ & $74,33^{\mathrm{a}}$ & $75,75^{a}$ & 4,02 \\
\hline $\begin{array}{l}\text { CDACNF } \\
C A D N F C\end{array}$ & $89,84^{\mathrm{a}}$ & $90,70^{\mathrm{a}}$ & 2,77 \\
\hline $\begin{array}{l}\text { CDAFDN } \\
C A D N D F\end{array}$ & $59,71^{\mathrm{a}}$ & $62,11^{\mathrm{a}}$ & 7,74 \\
\hline $\begin{array}{l}\text { CDAFDA } \\
C A D A D F\end{array}$ & $48,82^{\mathrm{a}}$ & $52,32^{\mathrm{a}}$ & 11,84 \\
\hline
\end{tabular}

Médias, na linha, seguidos de mesma letra não diferem $(P>0,05)$ pelo teste $\mathrm{T}$.

Means, in a row, followed by equal letter no differ $(P>.05)$ by $T$ test.

R. Bras. Zootec., v.32, n.6, p.1962-1968, 2003 (Supl. 2) 
7,44; e 4,05\%, respectivamente. Essa observação permite sugerir que, ao se incubarem alimentos ricos em energia, deve haver preocupação em aumentar a quantidade de material a incubar.

\section{Conclusões}

O aumento no valor energético das dietas melhora os coeficientes de digestibilidade de matérias seca e orgânica, carboidratos totais e não-fibrosos e reduz os coeficientes de digestibilidade da fibra em detergente neutro e fibra em detergente ácido.

A estimativa da produção de matéria seca fecal e estimativa da digestibilidade dos nutrientes podem ser efetuadas utilizando-se a fibra em detergente ácido indigestível como indicador interno em ovinos.

\section{Literatura Citada}

ALLEN, M.S. Relationship between fermentation acid production in the rúmen and requeriments for physically effective fiber. In: Symposium: meeting the fiber requeriments of dairy cows. Journal of Dairy Science, v.80, n.7, p.1447-1462, 1997.

BERCHIELLI, T.T.; ANDRADE, P.; FURLAN, C.L. Avaliação de indicadores internos em ensaios de digestibilidade. Revista Brasileira de Zootecnia, v.29, n.3, p.830-833, 2000.

CARDOSO, R.C.; VALADARES FILHO, S.C.; COELHO DA SILVA, J.F. et al. Consumo e digestibilidade aparentes totais e parciais de rações contendo diferentes níveis de concentrado, em novilhos F1 Limousin X Nelore. Revista Brasileira de Zootecnia, v.29, n.6, p.1832-1843, 2000.

CARVALHO, A.U.; VALADARES FILHO, S.C.; COELHO DA SILVA, J.F. et al. Níveis de concentrado em dietas de zebuínos. 1. Consumo e digestibilidade aparente. Revista Brasileira de Zootecnia, v.26, n.5, p.986-995, 1997.

COCHRAN, R.C.; ADMS, D.C.; WALLACE, J.D. et al. Predicting digestibility of different diets with internal markes: Evaluation of four potential markers. Journal of Animal Science, v.63, p.1476-1483, 1986.

COELHO DA SILVA, J.F.; LEÃO, M.I. Fundamentos de nutrição dos ruminantes. Piracicaba: Livroceres, 1979. 380p.

DUTRA, A.R.; QUEIROZ, A.C.; PEREIRA, J.C. et al. Efeito dos níveis de fibra e das fontes de proteína sobre o consumo e digestão dos nutrientes em novilhos. Revista Brasileira de Zootecnia, v.26, n.4, p.787-796, 1997.

FERREIRA, M.A.; VERAS, R.M.L.; CARVALHO, F.F.R. et al. Substituição parcial do milho moído pelo farelo de palma, como fonte de energia para ruminantes: consumo e digestibilidade aparente dos nutrientes. In: SIMPÓSIO NORDESTINO DE ALIMENTAÇÃO DE RUMINANTES, 8., 2000, Teresina. Anais... Teresina: SNPA, 2000. v.2, p.340.

FIDEPE- Informações municipais - Recife, 1982. Recife.

GALLOWAY, D.L.; GOETSCH, A.L.; FORSTER, L.A. et al. Feed intake and digestibility by cattle consuming bermudagrass hay supplemented with soybean hulls and (or) corn. Journal of Animal Science, v.71, n.11, p.3087-3095, 1993.

GRANT, R.J.; MERTENS, D.R. Development of buffer systems for $\mathrm{pH}$ control and evaluation of $\mathrm{pH}$ effects on fibber digestion in vitro. Journal of Dairy Science, v.75, p.1581-1587, 1992.

HUSSEIN, H.S.; MERCHEN, N.R.; FHEY JR., G.C. Effects of forage level and canola seed supplementation os site and extent of digestion organic matter, carbohydrates, and energy by streers. Journal of Animal Science, v.73, n.8, p.2458-2468, 1995.

ÍTAVO, L.C.V.; SILVA, F.F., VALADARES FILHO, S.C. et al. Indicadores internos para estimativa de produção fecal e digestibilidade de nutrientes em bovinos. In: REUNIÃO ANUAL DE DA SOCIEDADE BRASILEIRA DE ZOOTECNIA, 38., 2001, Piracicaba. Anais... Piracicaba: Sociedade Brasileira de Zootecnia, 2001. CD-ROM

MAHGOUB, O.; LU, C.D.; EARLY, R. J. effects of dietary energy density on feed intake, body weiht gain and carcass chemical composition of Omani growing lambs. Small Ruminant Research, v.37, p.35-42, 2000.

MERTENS, D.R. Analysis of fiber in feeds and its uses in feed evaluation and ration formulation In: SIMPÓSIO INTERNATIONAL DE RUMINANTES, REUNIÃO ANNUALDA SOCIEDADE BRASILEIRA DEZOOTECNIA, 29., 1992, Lavras. Anais... Lavras: Sociedade Brasileira de Zootecnia, 1992. p.1-32.

MERTENS, D.R. Creating a system for meeting the fiber requeriments of dairy cows. Journal of Dairy Science, v.80, n.7, p.14631481, 1997.

MERTENS, D.R. FDN fisicamente efetivo e seu uso na formulação de ração para vacas leiteiras. In: SIMPÓSIO INTERNACIONAL DE BOVINOCULTURA DE LEITE: Novos conceitos em nutrição, 2., 2001,Lavras. Anais...Lavras: Universidade Federal de Lavras, 2001. p.38.

NATIONAL RESEARCHCOUNCIL - NRC. Nutrientrequirements of sheep. 6. ed. Washington: National Academy Press . 1985. 99p.

ØRSKOV,E.R. New concepts of feed evaluation for ruminants with emphasis on roughases and feed intake. Asian Autralian Journal Animal Science, v.13 p.128-136. 2000.

SILVA, D.J. Análise de alimentos (Métodos químicos e biológicos). Viçosa, MG: Universidade Federal de Viçosa, 1990. 165p.

SNIFFEN, C.J.; O' CONNOR, J.D.; Van SOET, P.J. et al. A net carbohydrate and protein system for evaluating Cattle diets: II Carbohydrate and protein availability. Journal of Animal Science, v.70, p.3562-3577, 1992.

TIBO, G.C.; VALADARES FILHO, S.C.; VALADARES, R.F.D. et al. Níveis de concentrado em dietas de novilhos mestiços F1 Simental x Nelore. 1. Consumo e digestibilidades. Revista Brasileira de Zootecnia, v.29, n.3, p.910-920, 2000.

VALADARES FILHO, S.C.; BRODERICK, G.A., VALADARES, R.F.D. et al. Effect of replacing alfafa silage with high moisture corno n nutrient utilization and milk production. Journal of Dairy Science, v.83, n.1, p.106-114, 2000.

Van SOEST, P.J. Nutritional ecology of the ruminant. Ithaca: Comstock Publ. Assoc., 1994. 476p.

Van SOEST, P.J.; ROBERTSON, J.B.; LEWIS, B.A. Methods for extraction fiber, neutral detergent fiber and nonstarch polysaccarides in relation to animal nutrition. Journal of Dairy Science, v.83, n.1, p.3583-3597, 1991.

VÉRAS, A.S.C.; VALADARESFILHO, S.C.; COELHODA SILVA, J.F. et al. Consumo e digestibilidade aparente em bovinos Nelore, não-castrados, alimentados com rações contendo diferentes níveis de concentrado. Revista Brasileira de Zootecnia, v.29, n.6, p.2151-2156, 2000.

ZEOULA, L.M.; DIAN, P.H.M.; CALDAS NETO, S.F. et al. Avaliação de indicadores internos em ensaios de digestibilidade para ruminantes. In: REUNIÃO ANUAL DE DA SOCIEDADE BRASILEIRADEZOOTECNIA, 38., 2001, Piracicaba. Anais... Piracicaba: Sociedade Brasileira de Zootecnia, 2001.p.1122.

Recebido em: 03/10/02 Aceito em: 06/05/03 